\title{
Environmental blue light prevents stress in the fish Nile tilapia
}

G.L. Volpato ${ }^{1,2}$ and R.E. Barreto ${ }^{1}$
${ }^{1}$ Laboratório de Fisiologia Animal e Comportamento, Departamento de Fisiologia, Instituto de Biociências, and ${ }^{2}$ Caunesp, Universidade Estadual Paulista, Botucatu, SP, Brasil

\section{Correspondence \\ G.L. Volpato \\ Laboratório de Fisiologia Animal e \\ Comportamento \\ Departamento de Fisiologia \\ IB, UNESP \\ 18618-000 Botucatu, SP \\ Brasil \\ Fax: + 55-14-6821-3744 \\ E-mail: volpato@ ibb.unesp.br}

Presented at the XVI Annual Meeting of the Federação de Sociedades de Biologia Experimental, Caxambu, MG, Brazil, August 22-25, 2001.

Publication supported by FAPESP.

Received April 2, 2001

Accepted May 29, 2001

\section{Abstract}

The present study aimed to test the effects of blue, green or white light on the stress response of the Nile tilapia, Oreochromis niloticus (L.). Each color was tested on two groups of isolated adult Nile tilapia (8 replicates each): one being subjected to confinement stress, and the other not (control). A different environmental color was imposed on each compartment by covering the light source with cellophane of the respective color (green or blue; no cellophane was used for white light). The intensity of green, white and blue lights was 250, 590 and 250 lux, respectively. Basal plasma cortisol levels were determined for each fish prior to the experimental procedures. The fish were confined by being displaced toward one side of the aquarium using an opaque partition for $1 \mathrm{~h}$ both in the morning and the afternoon of the two consecutive days of the test. At the end of this 48-h period, plasma cortisol levels were measured again. Basal cortisol levels $(\mathrm{ng} / \mathrm{ml})$ were similar for each group (ANOVA, $\mathrm{F}_{(2 ; 42)}=0.77, \mathrm{P}=0.47$ ). Thus, plasma cortisol levels were analyzed in terms of variation from their respective basal level. After confinement, plasma cortisol levels were not increased in fish submitted to a blue light environment. Thus, blue light prevents the confinement-induced cortisol response, an effect not necessarily related to light intensity.

The visual environments of fish are blue, green or near infrared (1) and fish have cone cells which enable them to discriminate colors (2). Despite this, very few studies have been devoted to understanding the effects of background or light color on fish biology. Even so, some interesting effects have been reported. In salmonids, background color decreases egg development and increases egg mortality (3). In other fish families, effects of environmental color have also been described, such as changes in schooling, fright reaction, and color attractiveness in Sardinops caerulea (4), Oplegnathus fasciatus, Mono-

\author{
Key words \\ - Stress \\ - Animal welfare \\ - Light color \\ - Cortisol \\ - Nile tilapia \\ - O reochromis niloticus (L.)
}

canthus cirrhifer, Cybium niphonium, Spheroides niphobles, and Sphyraena japonica (5), and increased survival and growth in the Eurasian perch larvae, Perca fluviatilis (6).

The above mentioned studies show both improvement and disruption of fish welfare caused by environmental color, supporting the interest in better understanding such effects which may also be related to rearing conditions. In fisheries, the environmental conditions should undoubtedly be monitored to guarantee fish welfare. In these attempts, however, compatibility with tank color has been largely neglected. Actually, the inter- 
nal-wall color of the artificial fish environment has been chosen almost by chance.

The present study aims to understand the relation between welfare and environmental light color in the Nile tilapia, a fish where stress has been investigated (7-9) and which is considered to be the most extensively cultivated cichlid species in the world. Blue and green lights were tested because they are widespread in fish environments (1). Also, Loukashkin and Grant (4) and Kawamoto and Takeda (5) showed that fish are attracted to green and blue lights and avoid red light. Additionally, a previous study of the characid fish, Brycon cephalus, has suggested that these colors may affect reaction to stressors (10).

One hundred adults of the Nile tilapia, Oreochromis niloticus (Linnaeus, 1759), held for about one year in a 1200-1 tank, were the stock population. During this time, the water temperature averaged $24^{\circ} \mathrm{C}$, with continuous aeration through a biological filter and photoperiod from 6:00 to 18:00 h. Food was offered ad libitum once a day. Forty-eight fish were matched for size (mean $\pm \mathrm{SD}$ : standard length: $14.02 \pm 0.77 \mathrm{~cm}$; body weight: $110.16 \pm 19.01 \mathrm{~g}$ ) and randomly distributed in each experimental group. Sex was determined but no association with the results was found.

The effect of light color on stress was studied in Nile tilapia completely isolated in glass aquaria $(40 \times 25 \times 20 \mathrm{~cm})$ for 15 days before experimentation. Stress levels were determined basally and immediately after each color condition (blue, green and white) was imposed on stressed and nonstressed groups (six treatment; 8 fish each). After this experimentation period, the blood of all 48 fish was sampled for stress reevaluation.

The study was carried out in three completely isolated compartments. Each compartment was supplied with white fluorescent illumination. A different environmental color was imposed on each compartment by covering the light source with cellophane of the respective color (green or blue; no cellophane was used for white light). The intensity of light reaching each aquarium was: green $=250$, blue $=250$, and white $=590$ lux .

Each fish was displaced by an opaque partition which confined it to a small area (less than $10 \%$ of the total aquarium volume) for $1 \mathrm{~h}$, a method adapted from Auperin et al. (8). This confinement was imposed in the morning and afternoon of two consecutive days.

Throughout experimentation, water temperature averaged $26.47 \pm 0.78^{\circ} \mathrm{C}, \mathrm{pH}$ ranged from 6.2 to 6.5 , water was oxygen-saturated $(>5 \mathrm{mg} / \mathrm{l})$, and nitrite and ammonia were lower than $0.1 \mathrm{mg} / 1$ and $0.05 \mathrm{mg} / 1$, respectively. The photoperiod was set up from 6:00 to $18: 00 \mathrm{~h}$.

Stress was evaluated on the basis of plasma cortisol levels determined by radioimmunoassay. Each fish was anesthetized with benzocaine $(80 \mathrm{mg} / \mathrm{l})$ and blood was sampled $(\sim 0.6 \mathrm{ml})$ by cardiac puncture using heparinized (liquemine ${ }^{\circledR}$, Roche, Rio de Janeiro, RJ, Brazil) syringes. Blood was transferred to glass test tubes and centrifuged at $3000 \mathrm{rpm}$ for $10 \mathrm{~min}$. Plasma $(0.3 \mathrm{ml})$ was collected with a semi-automatic digital micropipette, transferred to 1-ml Eppendorf tubes and stored frozen $\left(-22^{\circ} \mathrm{C}\right)$ until required for assay.

Mean cortisol levels are shown in Table 1. Basal cortisol levels obtained for the six conditions (green, blue and white for stressed or nonstressed fish) were compared by ANOVA (Table 1). Since no significant difference was found, the difference between pre- and post-plasma cortisol was independently compared by the unpaired Student $t$ test between stressed and nonstressed groups for each color (Figure 1). Confinement increased cortisol levels in fish held in green and white light, but no effect occurred when these fish were maintained under blue light.

The present study showed that blue light prevents an increase of stress-induced cortisol in the Nile tilapia. 
A prior analysis was conducted to determine the reliability of the physiological responses expressed by the fish in this experiment. The Nile tilapia showed mean basal plasma cortisol levels ranging from 16.43 to $39.22 \mathrm{ng} / \mathrm{ml}$ (Table 1), which is in accordance with basal levels described in other studies for this and other fish species. Basal cortisol levels for the Nile tilapia ranging from 5 to $50 \mathrm{ng} / \mathrm{ml}$ and from 5 to $15 \mathrm{ng} / \mathrm{ml}$ were reported by Auperin et al. (8) and by Barcellos et al. (9), respectively. In a related cichlid, Oreochromis mossambicus, basal cortisol ranged from 20 to $60 \mathrm{ng} / \mathrm{ml}$ (11). Other studies have also shown similar basal results ranging from 10 to $50 \mathrm{ng} / \mathrm{ml}$ for other fish families, such as the cyprinid Cyprinus carpio (12), and the salmonids Oncorhynchus clarkii (13) and O. mykiss (14). As stated by Haddy and Pankhurst (15), it is difficult to establish basal levels of cortisol in fish mainly because of several factors which may be affecting their life, such as season, time of the day, etc. Despite this, confinement in the present study clearly increased cortisol, thus supporting the assertion that the fish were stressed compared with their previous condition.

The response of the fish held in the blue environment is interesting, showing inhibition of cortisol increase. Few studies have been devoted to the effects of color on fish and most of them are not directly concerned with stress. As far as we know, this is the first study showing such a cortisol-suppressing effect of environmental light color in fish. Other reports have focused on the effects of environmental color on behavior $(4,5,16)$, growth and survival (6). Effects of color background on chromatophore-regulating hormones have also been reported and Groneveld et al. (17) found that the response of the melanin-concentrating hormone to background color is not strictly related to the pituitary-interrenal axis in tilapia. However, the present study supports the idea that color influences this axis, thus showing that color may affect different biological systems.

The effects of environmental color have been investigated using mainly background color instead of light color. Although background color is probably more useful for recommendations of color of interior aquarium walls, light color - like those used in the present study - may also have practical consequences for indoor fish production or even fish transportation. Moreover, if the light color has an effect on fish physiology, the color of the inner walls of containers or aquaria should also be chosen accordingly.

Which color should this be? The present study showed that blue light was an effective inhibitor of the stress-induced cortisol response in the Nile tilapia. However, other colors have been shown to improve fish welfare in other species, such as green and blue in Sardinops caerulea (4), Oplegnathus fasciatus, Monocanthus cirrhifer, Cybium niphonium, Spheroides niphobles and Sphyraena japonica (5), green in Brycon cephalus (10), and light grey in perch larvae, Perca

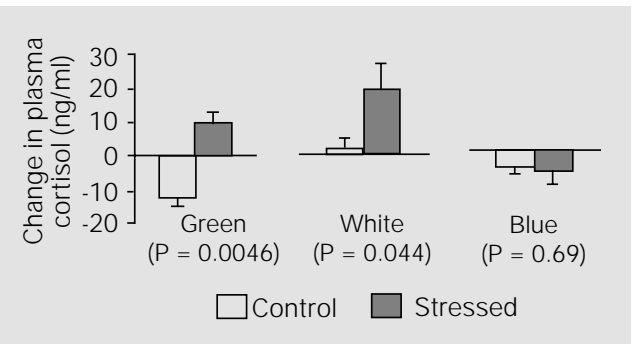

Figure 1. Effect of light colors on the stress response of adult Nile tilapia, Oreochromis niloticus. Data express the difference in plasma cortisol levels between the basal and posthandling conditions (see Table 1). $P$ values were obtained by the unpaired Student t-test for each color condition

Table 1. Mean ( \pm SD) plasma cortisol levels $(n g / m l, ~ N=8)$ of adult Nile tilapia, Oreochromis niloticus, before (basal) and after a color regime.

\begin{tabular}{lcccc}
\hline \multirow{2}{*}{ Group } & \multicolumn{3}{c}{ Light color } \\
\cline { 3 - 5 } & & Green & White & Blue \\
\hline \multirow{2}{*}{ Control } & Basal & $28.10 \pm 19.92$ & $16.43 \pm 6.54$ & $39.22 \pm 21.27$ \\
& Post-color regime & $15.64 \pm 7.88$ & $17.66 \pm 7.49$ & $34.61 \pm 15.58$ \\
Stressed & Basal & $37.95 \pm 12.94$ & $18.09 \pm 9.36$ & $34.01 \pm 25.12$ \\
& Post-color regime & $47.23 \pm 19.64$ & $35.83 \pm 21.87$ & $27.58 \pm 15.36$
\end{tabular}

The fish were isolated under a white-light regime (12-h light/12-h dark) for 15 days and then submitted to the color regime. Basal mean values were not statistically different from each other (ANOVA, $F_{(2 ; 42)}=0.77, P=0.47$ ). 
fluviatilis (6). In diurnal fish, vision is the main sensory modality (4) and cone cells have been reported to be present $(1,2)$, thus supporting an evolutionary significance for color discrimination in fish. Since in natural habitats environmental color is a characteristic which varies according to place, and may even change over time in the same habitat, the effect of color on the fish's life is expected to be associated with the predominant habitat color. According to Levine and MacNichol Jr. (1), the visual environments of fish are blue, green or near infrared, although the other studies cited above have shown mainly the two former colors as significant to the fish. Therefore, color effects on a fish's life seem to be a species-dependent phenomenon which may be related to specific habitat characteristics.

Fanta (16) argues that a blue background increases aggression in the Nile tilapia, and suggests that this color is not adequate for holding containers for this species. Conversely, the present data show that blue light has a protective role against stress for this same species. In fact, Schreck (18) suggests that conditions inducing behaviors differing from the standard pattern of the species may be supposed to be stressors, thus indicating that behaviors are reliable indicators of stress in fish. However, behavior interpretation must consider the environmental and evolutionary history of each species. Thus, aggression in the Nile tilapia should be interpreted considering its territorial habits (10). In fact, intraspecific aggression in territorial species is a natural behavior expected to be expressed when the fish are adjusted to their environment (stressors might decrease intraspecific aggression). Thus, the increased aggression caused by the blue background in the Nile tilapia reported by Fanta (16) may indicate that the fish were more comfortable. Volpato (10) reached a similar conclusion studying the effects of light color on matrinxã, Brycon cephalus. This fish was more aggressive under green light and grew almost three times as much in this color, a finding supporting that this increased intraspecific aggression might imply that these fish were unstressed. Therefore, we reinforce that blue light improves the welfare of the Nile tilapia.

A last comment concerns the effect of light intensity or light color. Light intensity has been shown to affect several processes in fish $(19,20)$ and light color or color background may affect light intensity. In the present study, the light intensities (measured in lux) of blue and green colors were the same, but the impact of these colors on the fish was strongly different. Thus, light intensity was probably not involved. The control condition showed a much higher light intensity; even so, these fish reacted in a manner similar to that of fish under green color (with a low lux value). Of course, these comments do not consider other light characteristics, such as wavelength. However, the present study emphatically shows that light color affects the life of Nile tilapia, opening new possibilities for further studies.

\section{Acknowledgments}

The authors thank Mr. A.C.B. Tardivo, Mr. H.L. Silva, Ms. A.T. Robiero and the Ph.D. student L.C. Jordão for very helpful technical assistance, Dr. E.C. Urbinati for allowing the cortisol analyses to be carried out in her laboratory (Caunesp, UNESP/Jaboticabal, SP, Brazil), and Mr. A.M.M.C. Gontijo for revising the English text and for suggestions about the initial draft of the manuscript. 


\section{References}

1. Levine J S \& MacNichol J rEF (1982). Color vision in fish. Scientific American, 216: 108-117.

2. Nicol J AC (1963). Some aspects of photoreception and vision in fishes. In: Russel FS (Editor), Advances in Marine Biology. Vol. 1. Photobehavior. Academic Press, London.

3. Heichenbach-Klinke HH (1982). Enfermedades de los Peces. Editora Acribia, Zaragoza, Spain.

4. Loukashkin AS \& Grant N (1959). Behavior and reactions of the pacific sardine, Sardinops caerulea (Girard), under the influence of white and colored lights and darkness. Proceedings of the California Academy of Sciences, 29: 509-548.

5. Kawamoto NY \& Takeda M (1951). The influence of wave lengths of light on the behavior of young fish. Report of Faculty of Fisheries, Prefectural University of Mie, 1: 41-53.

6. Tamazouzt $L$, Chatain $B \&$ Fontaine $P$ (2000). Tank wall colour and light level affect growth and survival of Eurasian perch larvae (Perca fluviatilis L.). Aquaculture, 182: 85-90.

7. Volpato GL \& Fernandes MO (1994). Social control of growth in fish. Brazilian J ournal of Medical and Biological Research, 27: 797-810.

8. Auperin B, Baroiller J F, Ricordel MJ , Fostier A \& Prunet P (1997). Effect of confinement stress on circulating levels of growth hormone and two prolactins in freshwater-adapted tilapia (Oreochromis niloticus). General and Comparative Endocrinology, 108: 35-44.

9. Barcellos LJ G, Nicolaiewsky S, de Souza SMG \& Lulhier F (1999). Plasmatic levels of cortisol in the response to acute stress in Nile tilapia Oreochromis niloticus (L.), previously exposed to chronic stress. Aquaculture Research, 30: 437-444.

10. Volpato $G L$ (2000). Aggression among farmed fish. In: Flos R \& Creswell L (Editors), Aqua 2000: Responsible Aquaculture in the New Millennium. European Aquaculture Society Special Publication, No. 28, Nice.

11. Vijayan MM, Pereira C, Gordon Grau E \& Iwama GK (1997). Metabolic responses associated with confinement stress in tilapia: the role of cortisol. Comparative Biochemistry and Physiology, 116C: 89-95.

12. Pottinger TG (1998). Physiological changes in carp, Cyprinus carpio L., retained in anglers keepnets. J ournal of Fish Biology, 53: 728-742.

13. Mesa MG \& Schreck CB (1989). Electrofishing mark-recapture and depletion methodologies evoke behavioral and physiological changes in cutthroat trout. Transactions of the American Fisheries Society, 118: 644-658.

14. Beaumont WRC, Lee MJ \& Rouen MA (2000). An evaluation of some electrical waveforms and voltages used for electric fishing; with special reference to their use in backpack electric fishing gear. J ournal of Fish Biology, 57: 433-444.

15. Haddy J A \& Pankhurst NW (1999). Stressinduced changes in concentrations of plasma sex steroids in black bream. J ournal of Fish Biology, 55: 1304-1316.

16. Fanta E (1995). Influence of background color on the behavior of the Oreochromis niloticus (Cichlidae). Arquivos de Biologia e Tecnologia, 38: 1237-1251.

17. Groneveld D, Balm PHM , Martens GJ M \& Wendelaar-Bonga SE (1995). Differential melanin-concentrating hormone gene-expression in 2 hypothalamic nuclei of the teleost tilapia in response to environmental changes. J ournal of Neuroendocrinology, 7: 527-533.

18. Schreck CB (1990). Physiological, behavioral, and performance indicators of stress. In: Adams SM (Editor), Biological Indicators of Stress in Fish. American Fisheries Symposium 8, Maryland.

19. Stefansson SO, Nortvedt R, Hansen TJ \& Taranger GL (1990). First feeding of Atlantic salmon (Salmo salar) under different photoperiods and light intensities. Aquaculture and Fisheries Management, 21: 481-487.

20. Stefansson SO, Hansen TJ \& Taranger GL (1993). Growth and parr-smolt transformation of Atlantic salmon (Salmo salar L.) under different light intensities and subsequent survival and growth in seawater. Aquacultural Engineering, 13: 231-243. 